How the College works

\title{
The formation of public policy
}

\author{
C. Thompson
}

I hope members might find it helpful if I set out why and how the College formulates policy and what it does with policies once it has them. This is an important matter since our voice needs to be heard clearly among the cacophony from all the other organisations which are - or want to be involved in mental health policy. There are indeed many of them. Some are professional organisations, some are patient or carer groups, some are charities such as the Mental Health Foundation. Others are related to providers such as the National Association of Health Authorities and Trusts (NAHAT), the independent hospitals or insurers. But perhaps the organisation with which we have most interaction in the formation of policy is the Department of Health, not of course because we always have congruent policies, but because they have the main government responsibility for mental health (although we have also recently negotiated successfully with the Department of Social Security over the rules on incapacity benefit).

These organisations have varying levels of expertise from which they draw their opinions, but none has the depth of experience in providing mental health services that we have. Our Members and Fellows have expertise at a senior level right across the range of the subject. Thus the Royal College has a voice which should be heard. With one or two notable exceptions, I have been impressed by the respect in which the College's experience and professional network is held by others. We therefore have a responsibility to make sensible, well-researched statements. That takes time and a procedure which can recruit the consensus of a significant part of the profession, and that means that we are not always as 'quick on our feet' as less well established organisations. Even so, through our Public Education Department we are now managing the public agenda in mental health to a much greater degree than we used to. The rest of this article describes how the College goes about 'making policy'.

Policy developments can start anywhere in the College - in sections, committees or special working parties. In the past we have occasionally got ourselves into a tangle at this stage by duplicating work unawares, for example in a Section working party and in Public Policy Committee (PPC). So we have changed the system. Now, all new policy initiattves come to the Public Policy Committee to be named and scoped. They are also referred to the Executive and Finance Committee (E\&F) which has the final say, and at that point the proposal is costed because we need to know that we can afford to do it. A Chairman is then nominated who is expected to work to a written remit and timetable, within general guidelines which have been agreed by PPC for all policy working groups. Increasingly, our policy is formed in partnership with other Colleges, health service organisations such as NAHAT, or other professional associations. A good deal of negotiation is necessary before starting work in such cases to ensure a successful conclusion without misunderstanding. All of this ensures that our work is now well focused, supported by the Officers, and not duplicated elsewhere within the College.

PPC also keeps record of, and requires frequent updates from, all currently active working groups. As Registrar one of my duties is to Chair this Committee, which is serviced by Public Education Department staff. This link with Public Education enables staff (and the Public Education Director, who is a member of PPC) to pick up on the issues of tomorrow and prepare press releases and conferences as necessary.

PPC is thus a policy think tank and management committee for the Executive and for Council. In fact it has two modes of action. First, it can identify areas of work which the College needs to carry out and suggest these to E \& F then processing them in the way described above. For example, in the last two years PPC has identified a need for a clear policy on the siting. staffing, structure and security of psychiatric units and work on this policy has recently started under the chairmanship of Professor Tom Burns and in collaboration with NAHAT, and the Royal College of Nursing (RCN). We also identified a need to set standards for a place of safety under section 136 and we hope to start work on this shortly. We are completing work on sexual abuse and harassment in psychiatric settings, and just 
beginning on risk assessment and clinical risk management, and on recovered memory syndrome.

Second, PPC responds to requests for comment on documents recelved from outside the College (and there are many of these - showing how much our view is sought) and from within the College. This is often a complicated task and we usually operate by identifying a member of the Committee who will read the document carefully and present it for discussion. Some of these documents are huge, others are deceptively brief. Some of them are important, others are irrelevant. The trick is to discriminate early enough so as not to waste time on the irrelevant and to give plenty of time to the important. There is wide representation from all over the College on PPC so there is usually an expert on any given topic whose lapel I can usefully finger for an opinion! One kind of document we always take very seriously is the report of an Inquiry. Increasingly we are becoming concerned about the scapegoating of consultants and the inadequate analysis of the local political and financial situation in these documents. Clearly some are better than others but many are of a very inferior standard. We are considering how best to act, but in the meantime the Research Unit, which has an active link with PPC, is carrying out some research to analyse Inquiry reports.

PPC decided in 1994 that it needed more expert help on two areas and it has therefore set up two new sub-committees which operate like expert advisory groups. These are on Mental Health Law and Parliamentary Liaison respectively.

The Law group has given itself a number of tasks to do, not the least of which is to review the Mental Health Act 1983 from the standpoint of modern community care and legal principles including those of the European Union. The group has already proved invaluable help in our response to the Mental Health (Patients in the Community) Bill, the Law Commission's influential report on mental incapacity and the revision to the Irish mental health law. Members of the group are also planning a regular law report in the Psychiatric Bulletin to help College Members keep up to date.

The Parliamentary Liaison Committee has the task of ensuring that relations between the profession and law-makers are as positive as they can be. This is a special form of public education and several types of activity have been suggested. These include central initiatives such as regular meetings with the All Party Group on Mental Health (currently serviced by the College staff) and with the health spokespersons for all the main partles. They also include plans for individual Members to make contact with their local MPs. In so doing our Members may discover whether their MP has any interest in mental health and what he/she believes the issues to be in their constituency. They may also wish to invite them to visit the psychiatric facilities to see for themselves the good and bad points of the service. Often Members find when they do this that their MP has a professional or personal interest in mental health or social services which would make them an ally in pushing through much-needed improvements. Of course this is not always the case! We are very keen to hear from any Members who know of MPs who have shown an interest as we now keep our own register. Contributions to Gary Robjent in the College's Public Education Department please.

PPC's third subgroup is the Special Committee on Unethical Psychiatric Practices (SCOUPP) which is now the Ethics sub-committee of PPC. This Committee is ably chaired by Dr Jim Birley and, like the other advisory groups, it controls its own agenda so it can bring to the College's attention international or domestic ethical matters which it believes need new policies. SCOUPP was formed to tackle the College's contribution to the opposition to Soviet abuse of psychiatry and more recently has instituted discussions about poor performance procedures as well as many other important ethical topics. It is not an ethics committee in the sense of investigating individual cases of poor ethical practice.

Once PPC has created and approved a policy document it comes to $E \& F$ which may then consult more widely to ensure consensus. When E \& F believes the document is ready it goes to Council which might make further adjustments or spot a problem E \& F had not noticed, in which case it is sent back for further work. This does take time but we need to get our statements right because they are important. The great advantage of this system, time consuming though it may be, is that policies in specialist areas, after being approved by Council, emerge from the College with the full agreement and force of the entire profession.

Policies do not last forever. All new policy documents are now given a 'currency'. Usually this is five years but it may be sooner if we think it will become out of date quickly. We also have a computerised database in the Library of all Council-approved policies which have been made since the inception of the College and which PPC is now reviewing. Some of these policies need archiving for the historians, some need revising and some can stand unchanged for another five years. In a few years time all our extant policy statements will be confirmed as current. They will comprise an unparalleled source of informed opinion about mental health services and will be contained in the series of documents called Council Reports and numbered consecuttvely. A 
list of available reports is often published in the Psychiatric Bulletin and can be obtained from the College.

Chris Thompson, Registrar, The Royal College of Psychiatrists
This is one of a series of articles about the way the College works. The Registrar would be interested to recetve suggestions and comments from Members, Fellows and trainees

\section{New Council Report}

\section{Strategies for the Management of Dis- turbed and Violent Patients in Psy- chiatric Units}

This is a joint review by the Royal College of Psychiatrists and the Royal College of Nursing of their policies for the overall management of violence and aggression in hospitalised patients. It stemmed from the widespread and wellfounded concern about the potential for the misuse of selection and examines alternative approaches.

The emphasis of the report is on the prevention of violence with a reduction in aggression. There is an account of a therapeutic regimen which might serve as a model for in-patient units. This regimen demands a substantial investment in the ward environment as well as in staff training, support and supervision, as much will depend on the attitudes of staff to violence and its management. Also considered is the part to be played by different professions in a multidisciplinary approach. A central element is the assessment of risk as is the involvement of the patient in the strategy of his/her treatment.

Although often misused, medication has an important and useful place in treatment, but must be subject to frequent and careful review.

Restraint should be subject to the formal framework of 'control and restraint' techniques which require supervised training and monitoring. The nature and place of restraint requires further scrutiny.
Seclusion is an emergency measure to be used only where there is a significant risk of harm to the patient or others. It should be used as infrequently as possible and only for as long as it takes for the patient to return to a calmer frame of mind. In short, it should be a short-lived 'fireextinguisher' and should not form part of any therapeutic programme. Although it was suggested that it be phased out altogether, there remain some occasions when alternatives are inadequate or more unpleasant. Furthermore, its removal should carry the risk that the practice would continue but under another name: seclusion has the advantage that its use is controlled. recorded and externally monitored.

Indeed, any form of emergency response should be recorded systematically, subject to audit, and be brought to the attention of the Unit's managers and purchasers. The appendices include various sample reporting forms.

Also appended is a consensus protocol for a broader approach to the management of aggression. including out-patients, which was prepared by the Section for the Psychiatry of Learning Disability. Finally there is a comprehensive bibliography.

The full report (please quote CR41) is available from the College Publications Department (Kerstin Sayoud, ext. 146) at a cost of $\$ 5$ per copy. 